to note that at $p \mathrm{H} 6.2$ a further splitting of the half-

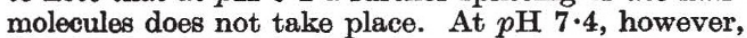
both halves and molecules of smaller size are formed. By means of suitable filters, it was found that the photochemical action is confined to the region of wave-length in which the 'protein part' of the molecule absorbs $(2 \cdot 800 \mathrm{~A}$. and shorter wave-lengths). The band corresponding to the absorption of the prosthetic group $(3 \cdot 700-3 \cdot 200 \mathrm{~A}$.) is inactive.

From these observations we conclude that the weakest bond in the molecule of Helix hæmocyanin is that holding the two halves together. To split up further by ultra-violet light the half-molecules, an increase in the number of ionized groups is necessary.

We hope to gain further information by extending these experiments to other high-molecular proteins and by using other kinds of energy quanta.

Institute of Physical Chemistry, Sven Brohulis.

University, Uppsala. Sept. 30.

1 Svedberg, T., NATURE, 139, 1051 (1937).

2 Bernal, J. D., and co-workers, NATURE, 141, 521 (1938). Astbury, W. T., Trans. Faraday Soc., 34, 378 (1938).

${ }^{3}$ Cf. Jordan, P., Phys. Z., 39, 345 (1938).

' Brohult, S., NATURE, 140, 805 (1937).

\section{Association of Unlike Molecules through Hydrogen Bonds}

In donor solvents, such as acetone and dioxan, the position of the $\mathrm{OH}$ fundamental of water, alcohols, or phenol depends upon the solvent so as to indicate hydrogen bond formation between the solute and the solvent ${ }^{1}$. Using $\mathrm{CH}_{3} \mathrm{OD}, \mathrm{I}$ have extended the work on alcohol mixtures to include new solvents, many of which absorb in the $3 \mu$ region and hence cannot be studied with ordinary alcohol. Most of the amines apparently form very strong hydrogen bonds with an $\mathrm{OH}$ or an OD group-that is, in general they produce longer shifts in the OD band than do oxygenated solvents like ethers and esters.

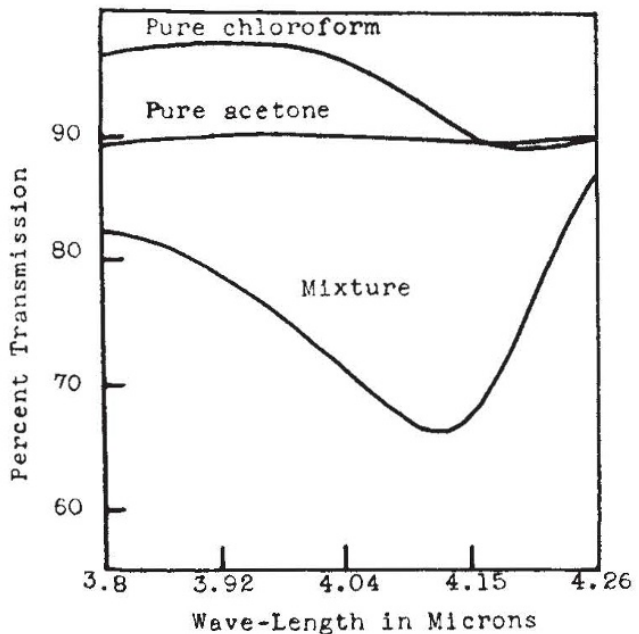

Assootation BAND IN CHLOROFORM-ACETONE MIXTURE (MOLE FRACTION 0.5 ; CELL THICKNESS 0.015 CM.).

An interesting case of association between unlike molecules is that of chloroform with other liquids ${ }^{2}$. I have observed an associational band in the region of $4 \mu$ for mixtures of chloroform with donor solvents such as pyridine, ether and acetone. Considering, with other factors, the position of the band and the manner of its variation in position and intensity for the different mixtures, I believe it to be an $\mathrm{NH}$ or an $\mathrm{OH}$ vibrational band resulting from a hydrogen bond formed by the sharing of the proton of the $\mathrm{CH}$ chloroform group with the $\mathrm{N}$ or $\mathrm{O}$ of the solvent. One of the bands is shown in the accompanying diagram. A similar, but weaker, associational band was found for some bromoform solutions. In all previous infra-red studies of hydrogen bonding, only shifts in the bands of either the solute or solvent were observed-no new bands were found. This seems to be the first direct observation of the new band which would be found in any case of hydrogen bonding, and hence I consider it the most definite evidence yet given for the existence of hydrogen bonds.

A more complete report of these results will appear elsewhere.

Mendenhall Laboratory of Physics,

WALTER GORDY.

Ohio State University, Columbus, Ohio. Sept. 14.

' Gordy, W., J. Chem. Phys., 4, 749 (1936); J. Amer. Chem. Sor: 60, 605 '(1938); Gordy, W., and Nielsen, A. H., J. Chem. Phys. 6, 12 (1938).

2 Macleod and Wilson, Trans. Faraday Soc., 31, 596 (1935); Glasstone, S., Trans. Faraday Soc., 23, 200 (1936); Gordy, W., J. Amer, Marvel, C.'S., J. Amer. Chem. Soc., 60, 1337 (1938).

Very Small Intensity of the Red Or Triplet during the Auroral Displays of September 14-16

IT has been shown in previous papers ${ }^{1,2}$ that the red aurora of type $A$ owes its redness to the enhancement of the red OI-triplet $\left({ }^{1} D_{2}-{ }^{3} P_{0,1}, 2\right)$ and that the relative intensity of this triplet and the frequency of the red auroras of type $A$ seem to follow the sunspot frequency ${ }^{2,3}$. This rule was found to hold for spectrograms obtained since 1923 and up to the winter season 1937-38.

As we approached the present sunspot maximum, the red auroras of this $A$-type and the intensity of the red. triplet became very pronounced indeed. On spectrograms obtained during the winters 1936-37 and 193738 , the red line 6300 was usually about equally as strong as, and sometimes much stronger than, the green line $e^{3,4,5}$.

Very brilliant auroral displays appeared at Oslo during the two nights September 14-15 and 15-16 this autumn. On both nights we took several auroral spectrograms on panchromatic plates (Agfa Isopan). Although the green line

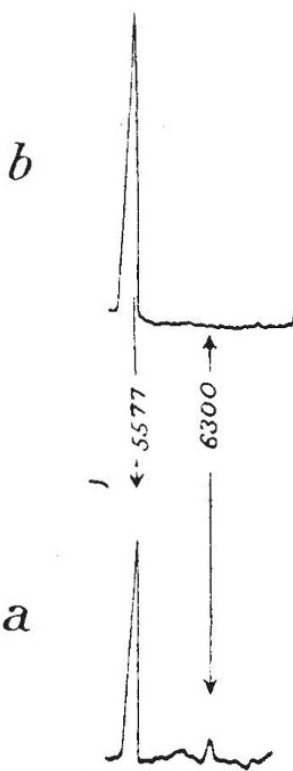

a. Sept. 14-15, 1938 ; exp. 2320-0025

b. Sept. 15-16, 1938; exp. 2045-240 5577 appeared with great density on the plates, the red line 6300 was only just visible on one of the spectrograms. The result is illustrated in the accompanying 